\title{
Comparison of SAR-interferometric and surveyed velocities on a mountain glacier: Black Rapids Glacier, Alaska, U.S.A.
}

\author{
B.T. Rabus, ${ }^{*}$ D. R. FATland \\ Geophysical Institute, University of Alaska Fairbanks, Fairbanks, Alaska 99775-7230, U.S.A.
}

\begin{abstract}
An interferogram reflecting the motion of Black Rapids Glacier, Alaska, U.S.A., was obtained from two European Remote-sensing Satellite (ERS-1) syntheticaperture radar (SAR) images, acquired on 22 and 25 January 1992. We investigate whether the interferometric data are quantitatively consistent with terrestrial velocity measurements along three transverse profiles. These terrestrial data are from different years (1987, 1990, 1996) and cover different periods (6-28 April, 23 May-7 July and a whole year) than the SAR interferogram. Terrestrial ice velocity at the date of the SAR imagery is obtained via seasonal and annual corrections that are calculated from other terrestrial velocity measurements available at higher time resolution for selected sites on the glacier. Interferometric and terrestrial velocity are in excellent agreement if a (terrestrially measured) surface-normal velocity component $\left(v_{\perp}\right)$ is properly accounted for. This suggests that both the interferometric velocities and the conversions of terrestrial data to the winter period are reliable. The terrestrial velocity measurements show that ice flow in the upper ablation area (14-16 km sites) changes from longitudinal compression in mid-winter $\left(v_{\perp}=\right.$ $\left.+0.82 \mathrm{~cm} \mathrm{~d}^{-1}\right)$ to moderate longitudinal extension during summer $\left(v_{\perp} \approx-0.25 \mathrm{~cm} \mathrm{~d}^{-1}\right)$. In the lower ablation area, the seasonal variations of the longitudinal strain rate are much smaller: +1.0 and about $+0.85 \mathrm{~cm} \mathrm{~d}^{-1}$ for the respective mid-winter and summer values of $v_{\perp}$ at the $20 \mathrm{~km}$ site.
\end{abstract}

\section{INTRODUGTION}

Measurements of the spatial distribution of surface velocity and its changes on various time-scales are an important tool for studying deformational and basal processes on glaciers. Examples of such processes are the evolution of the basal drainage underneath surge-type glaciers during quiescent and surge modes (Bindschadler, 1982; Kamb, 1987; Heinrichs and others, 1996), and the distribution of mass flux in continental ice sheets which determines their current mass balance (e.g. Kostecka and Whillans, 1988).

The surface velocity of glaciers is traditionally measured by repetitive terrestrial surveying of markers on the ice surface. This method allows evaluation of mean velocities over interannual to sub-daily time-scales. A drawback to this method is that usually only a few markers can be monitored, whose spatial distribution is often unable to reveal interesting two-dimensional features of the velocity field. The traditional method requires field occupation, which can be expensive and time-consuming on large glaciers and ice fields.

Interferograms combining two or more successive synthetic-aperture radar (SAR) phase-amplitude images offer the possibility of determining surface velocity over a two-dimensional domain at a spatial resolution of about $30 \mathrm{~m}$ (e.g. Goldstein and others, 1993). The better spatial coverage of SAR interferometry compared to terrestrial measurements is, however, accompanied by several restrictions. The first is

\footnotetext{
* Present address: Remote Sensing Section, German Aerospace Research Establishment (DLR), Oberpfaffenhofen, D-82234 Wessling, Germany.
}

that only the velocity component in satellite look direction can be measured. Another restriction is that the time interval over which velocity can be evaluated depends on the satellite repeat cycle (1, 3 or 35 days for the European Remotesensing Satellite (ERS), depending on the mode of operation) and on the temporal coherence of the signal. Owing to weather-induced changes, most temperate-glacier surfaces decorrelate after only a few days. For polar ice sheets on the other hand, high-quality interferograms can be obtained over periods of 35 days or more. Further restrictions are the need to identify tie points for calibrating the baseline and tying the SAR imagery to a map projection; the effects of atmospheric disturbances on the interferometric phase; and the difficulties involved with the required phase unwrapping (e.g. Goldstein and others, 1988). Finally there are operational constraints on when satellite data are acquired and made available.

In this paper, we make a quantitative comparison of SAR interferometric velocity measurements with existing terrestrial survey data. Additionally, some new aspects of the seasonal ice dynamics of Black Rapids Glacier, Alaska, U.S.A., are discussed.

\section{Background on Black Rapids Glacier}

Black Rapids Glacier is a large, surge-type glacier located at $63^{\circ} 30^{\prime} \mathrm{N}, 146^{\circ} 30^{\prime} \mathrm{W}$, in the central Alaska Range (Fig. la and b). Only one surge, in 1936-37, has been directly observed, but surge periods observed on neighboring glaciers of comparable size have lasted 50-75 years (Clarke, 1991; Harrison and others, 1994). The main ice body is about $40 \mathrm{~km}$ long and covers an elevation range of 1000-2500 $\mathrm{m}$. 

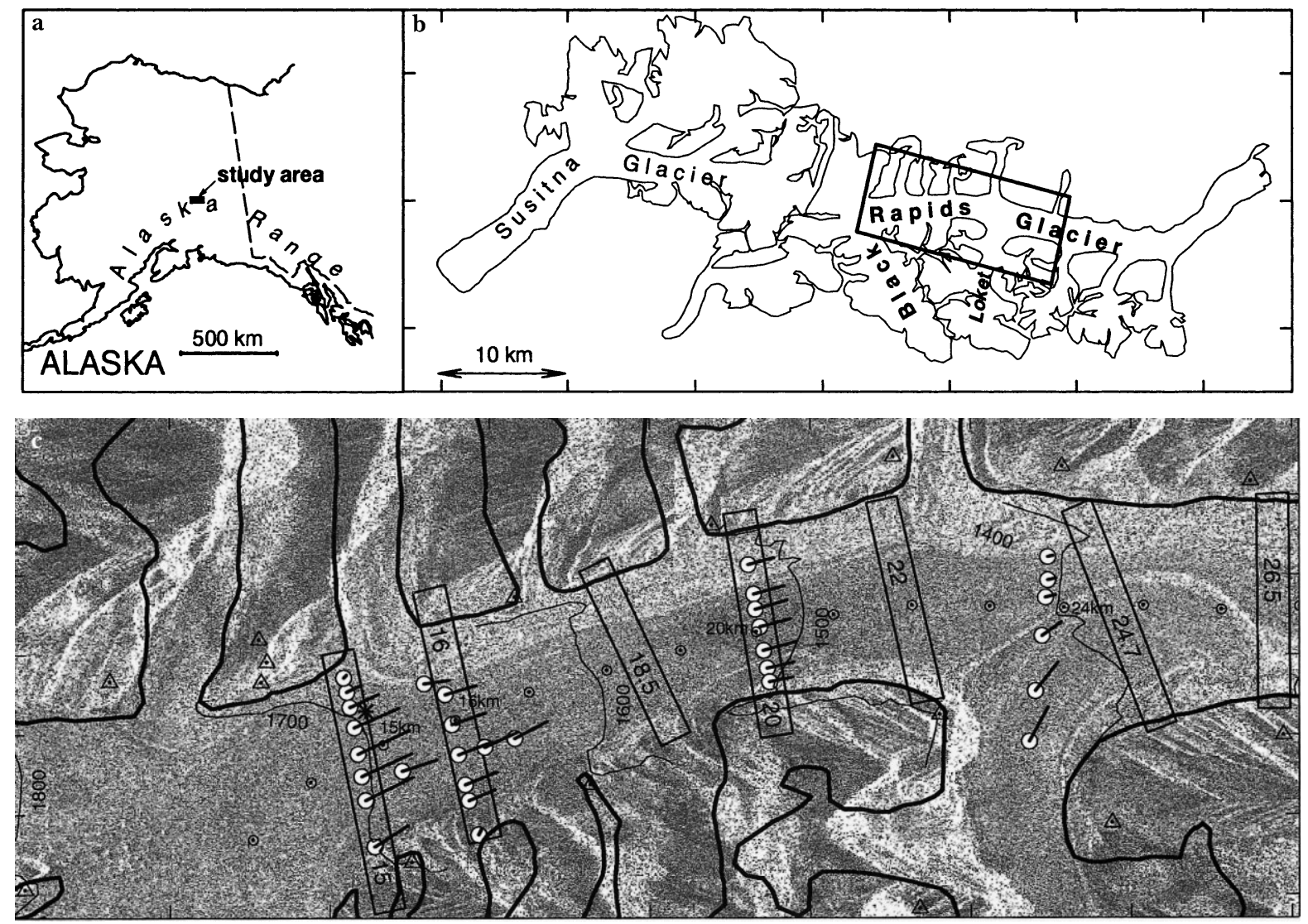

Fig. 1. (a) Overview map. (b) Map of Black Rapids Glacier with study area. (c) SAR amplitude image of the study area. Coregistered locations of survey motion markers (large circles), center-line markers (small circles), terrestrial survey monuments (triangles) and the glacier outline (solid line) are superimposed. The rectangular regions specify where phase was unwrapped to obtain interferometric velocity profiles.

The ablation area occupies an east-west oriented valley, which is a branch of the extensive Denali fault zone that divides the Alaska Range parallel to its crest. In contrast, most of the accumulation area is located in two north-south oriented valleys, one of which forms the source of a major tributary that joins Black Rapids Glacier about $25 \mathrm{~km}$ from its head (denoted "Loket" in Fig. 1b).

Black Rapids Glacier has been monitored regularly since 1971 in a joint effort of the U.S. Geological Survey and the University of Alaska Fairbanks (Heinrichs and others, 1995, 1996). Surface velocity was usually measured twice per year together with surface elevation and mass balance at ten sites along the center line. In some years, several transverse velocity profiles were also surveyed. At selected sites velocities at higher time resolutions of several weeks to several times daily were measured using automatic camera measurements or theodolite surveys.

Annual surface velocities for 1971-95 are shown in Figure 2a (adapted from Heinrichs and others, 1996) for the 14 and $20 \mathrm{~km}$ sites (names refer to center-line distance from glacier head; see Fig. 1c). The velocity at these and most other sites shows synchronous interannual fluctuations of about $\pm 20 \%$ with "periods" of 4-9 years. Superimposed on this long-term evolution of the annual velocities is a winter/summer oscillation of similar magnitude. Figure $2 \mathrm{~b}$ shows this seasonal velocity cycle at 1 month time resolution for markers near the 15 and $20 \mathrm{~km}$ sites as compiled from automatic camera measurements in four different years (Heinrichs and others, 1995; unpublished data from M. Truffer). The seasonal velocity cycle is similar at the two sites. Velocity is lowest for OctoberDecember and sharply increases around the end of May to reach its annual high in June. The monthly values of indi- vidual years typically agree with each other to within $\pm 10 \%$ at a given site. It is important to note that the interannual trend shown in Figure $2 \mathrm{a}$ is not solely caused by the long-term changes in summer velocities (black dots in Fig. 2a) but also reflects changes in the mid-winter (November-February) velocities. Thus the annual velocity state of Black Rapids Glacier can be estimated from SAR interferometry in midwinter, when phase coherence tends to be highest due to weaker weather-related surface change.

Interferograms of Black Rapids Glacier have a maximum motion contribution due to the coplanarity of the main glacier flow with the ERS look direction. This geometry also prevents shadowing from the surrounding mountains. (For ERS, shadowing is caused by slopes, which exceed $23^{\circ}$ in satellite look direction.) The data used in this study have a small baseline, which means a generally low sensitivity of the interferometric phase with respect to topography. For the glacier surface with its low vertical relief of $35 \mathrm{~m}$ per $1 \mathrm{~km}$ horizontal distance along-glacier and a mere few meters across-glacier, the topographic phase contribution is particularly small.

\section{INTERFEROMETRIC VELOGITY MEASUREMENTS}

Two ERS-1 SAR phase-amplitude images of the Black Rapids/ Susitna Glacier area acquired on 22 and 25 January 1992 were used in this study. The images were co-registered and were processed to obtain the wrapped interferometric phase following the methods outlined by Fatland and Lingle (1998). Figure lc shows the average signal amplitude of the two images for the subscene indicated in Figure lb. The interferometric phase $\Phi$ 

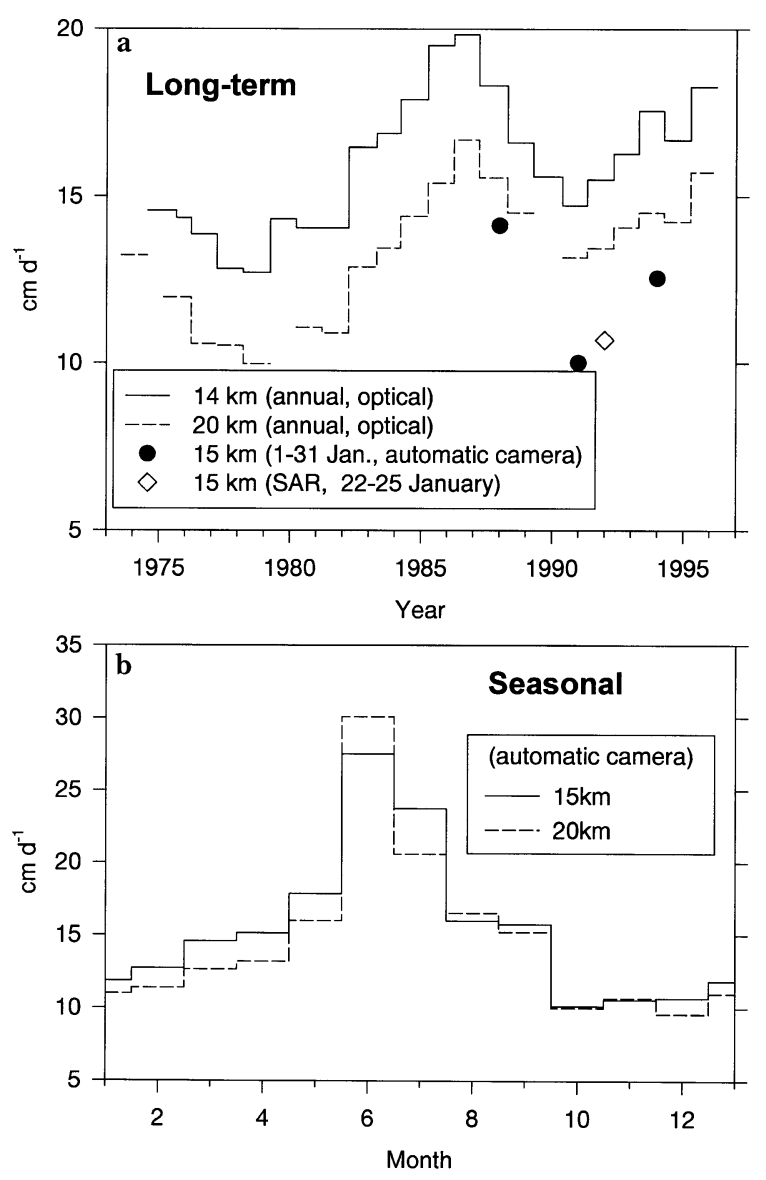

Fig. 2. Velocity variations of Black Rapids Glacier at the 14, 15 and $20 \mathrm{~km}$ sites: (a) interannual velocity variations $1971-$ 95; (b) average seasonal velocity variation evaluated from automatic camera measurements, 1985-95 (both compiled from Heinrichs and others, 1995, 1996; unpublished data from $M$. Truffer). The diamond-shaped symbol denotes the interferometric result of this study.

between the two images contains independent contributions from orbit geometry (o), surface topography $(\mathrm{t})$, surface motion $(\mathrm{m})$, atmospheric changes $(\mathrm{a})$ and sensor noise $(\mathrm{n})$ :

$$
\Phi=\Phi_{\mathrm{o}}+\Phi_{\mathrm{t}}+\Phi_{\mathrm{m}}+\Phi_{\mathrm{a}}+\Phi_{\mathrm{n}} .
$$

Here, orbit geometry and topography are both understood relative to a spherical model Earth. $\Phi_{\mathrm{o}}$ was removed by starting with the baseline information from the European Space Agency database. Residual phase ramps in range and azimuth, stemming from inaccuracies of the baseline estimate, were subsequently eliminated by using three-phase tie points on unglaciated terrain. Differences in elevation between these tie points are taken from a topographic map and converted to phase (via Expression (2); see below). They are compared to corresponding differences in absolute phase obtained by hand-counting $2 \pi$-cycles of the relative phase (termed fringes) between the tie points in the interferogram. The remaining phase signal, $\Phi-\Phi_{\mathrm{o}}$ is shown in Figure 3 for the subscene of Figure 1c. Phase values are restricted to $[0,2 \pi]$ (wrapped phase), which is mapped to [white, black] using 256 linearly spaced gray-scale values.

Under extreme circumstances, changes in atmospheric water content between the two SAR acquisitions can cause $\Phi_{\mathrm{a}}$ to be on the order of one fringe or larger (e.g. Goldstein, 1995; Hannsen and others, in press). For the dry winter climate of interior Alaska, however, $\Phi_{\mathrm{a}}$ is expected to be smaller. Gray and others (1997) find values of \pm 0.25 fringes over the Canadian Arctic, which has a similar climate. As most atmospheric distortions are large-scale (several $\mathrm{km}$ ), effective values will be still smaller in our case because we calibrate the interferometric phase for each of the short velocity profiles separately. The combined contributions from atmospheric changes and sensor noise $\left(\Phi_{\mathrm{a}}+\Phi_{\mathrm{n}}\right)$ are thought to represent a random error of $<0.2$ fringes.

The surface topography $h$ and the surface-parallel velocity $v_{\|}$are linked via image geometry to the remaining contributions $\Phi_{\mathrm{t}}$ and $\Phi_{\mathrm{m}}$ as follows:

$$
h \approx \frac{\lambda r \sin \theta}{4 \pi B_{\mathrm{n}}} \Phi_{\mathrm{t}}
$$

$$
\begin{aligned}
& v_{\|}= \\
& \lambda \sqrt{\frac{1-\left[\sin \alpha_{\mathrm{V}} \cos \alpha_{\mathrm{G}}-\cos \alpha_{\mathrm{V}} \sin \alpha_{\mathrm{G}} \cos \left(\beta_{\mathrm{V}}-\beta_{\mathrm{G}}\right)\right]^{2}}{4 \pi \Delta t\left(\sin \theta \cos \alpha_{\mathrm{V}} \cos \beta_{\mathrm{V}}-\cos \theta \sin \alpha_{\mathrm{V}}\right)}} \Phi_{\mathrm{m}},
\end{aligned}
$$

where $\lambda=5.66 \mathrm{~cm}$ is the wavelength of the SAR signal, $\Delta t=3 \mathrm{~d}$ is the time interval between the image acquisitions, $B_{\mathrm{n}} \approx 24 \mathrm{~m}$ is the orbit separation normal to the satellite look direction, $r$ is the slant-range distance and $\theta$ is the incidence angle of the SAR signal with respect to the Earth radius vector. $B_{\mathrm{n}}$ depends weakly on $r$, but since our analysis will use only small, independently calibrated patches of the interferogram, we can neglect this effect. $\theta$ is

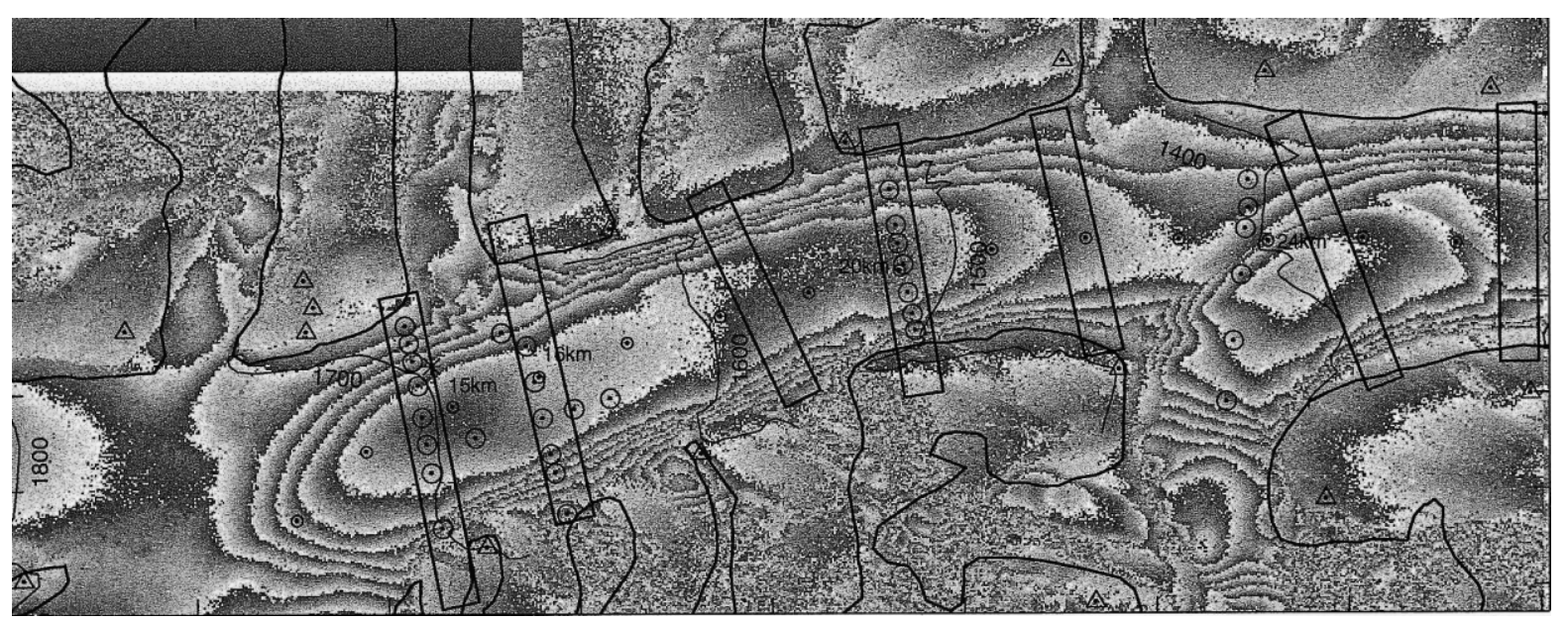

Fig. 3. Interferogram of Black Rapids Glacier evaluated from ERS-1 SAR imagery on 22 and 25 January 1992. Shown is the wrapped phase with the flat Earth signal removed for the same area as Figure 1c. 
calculated from elevation $h$ and slant-range distance $r$ according to

$$
\theta=\arccos \left[\frac{H^{2}-\left(R_{\mathrm{E}}+h\right)^{2}-r^{2}}{2\left(R_{\mathrm{E}}+h\right) r}\right],
$$

where $H$ and $R_{\mathrm{E}}$ are the distance satellite-to-center-ofEarth and the local Earth radius, respectively.

Equation (3) is derived by using an $x-y-z$ Cartesian coordinate system according to Figure 4, with $z$ vertical, $y$ along flight track and $x$ along ground-range track. In Figure $4, \alpha_{\mathrm{G}}$ and $\beta_{\mathrm{G}}$ are slope and aspect of the glacier surface, respectively, while $\alpha_{\mathrm{V}}$ and $\beta_{\mathrm{V}}$ are the corresponding quantities for the ice-velocity vector $\mathbf{v}$. The surface-parallel velocity component is given by $\mathbf{v}_{\|}=\mathbf{v}-\left(\mathbf{v} \cdot \mathbf{n}_{\mathrm{G}}\right) \mathbf{n}_{\mathrm{G}}$, where $\mathbf{n}_{\mathrm{G}}$ is the unit-normal vector of the ice surface. Using the coordinate representations $\mathbf{v}=v\left\{-\cos \alpha_{\mathrm{V}} \cos \beta_{\mathrm{V}},-\cos \alpha_{\mathrm{V}} \sin \beta_{\mathrm{V}},-\sin \alpha_{\mathrm{V}}\right\}$ and $\mathbf{n}_{\mathrm{G}}=$ $\left\{-\sin \alpha_{\mathrm{G}} \cos \beta_{\mathrm{G}},-\sin \alpha_{\mathrm{G}} \sin \beta_{\mathrm{G}}, \cos \alpha_{\mathrm{G}}\right\}$ we obtain

$v_{\|}=v\left\{1-\left[\sin \alpha_{\mathrm{V}} \cos \alpha_{\mathrm{G}}-\cos \alpha_{\mathrm{V}} \sin \alpha_{\mathrm{G}} \cos \left(\beta_{\mathrm{G}}-\beta_{\mathrm{V}}\right)\right]^{2}\right\}^{\frac{1}{2}}$.

For $\beta_{\mathrm{G}} \approx \beta_{\mathrm{V}}$ (see discussion below) the latter expression is well approximated by $v_{\|} \approx v \cos \left(\alpha_{\mathrm{G}}-\alpha_{\mathrm{V}}\right)$. The velocity projected in satellite look direction is given by $\mathbf{v}_{\mathrm{LOS}}=$

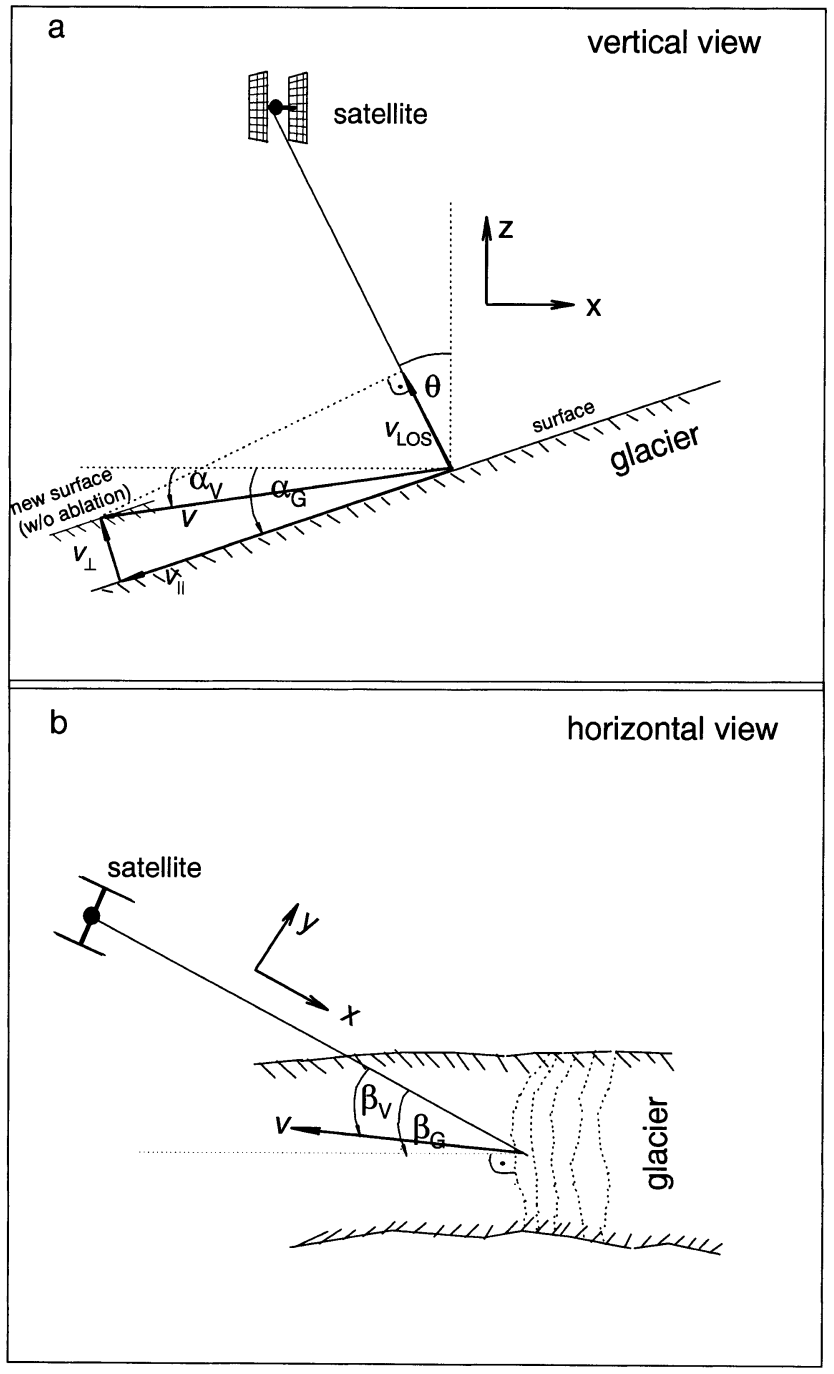

Fig. 4. Interferometric imaging geometry, (a) vertical and (b) horizontal view, used to derive the relation between the motion phase $\Phi_{\mathrm{m}}$ and the surface-parallel velocity $v_{\|}$. The general case $\alpha_{\mathrm{V}} \neq \alpha_{\mathrm{G}}, \beta_{\mathrm{V}} \neq \beta_{\mathrm{G}}$ is shown; the assumptions that ice flow is surface-parallel and normal to topographic contours correspond to $\alpha_{\mathrm{V}}=\alpha_{\mathrm{G}}$ and $\beta_{\mathrm{V}}=\beta_{\mathrm{G}}$. $\left(\mathbf{v} \cdot \mathbf{n}_{\text {LOS }}\right) \mathbf{n}_{\text {LOS }}$. With the coordinate representation $\mathbf{n}_{\mathrm{LOS}}=\{-\sin \theta, 0, \cos \theta\}$ we obtain

$$
\mathbf{v}_{\mathrm{LOS}}=v\left(\cos \alpha_{\mathrm{V}} \cos \beta_{\mathrm{V}} \sin \theta-\sin \alpha_{\mathrm{V}} \cos \theta\right) .
$$

Combining the geometric expressions for $v_{\|}$and $\mathbf{v}_{\text {LOS }}$ with the interferometric formula $\mathbf{v}_{\mathrm{LOS}}=\lambda \Phi_{\mathrm{m}} /(4 \pi \Delta t)$, we arrive at Equation (3). Using multiple interferometry on ascending and descending satellite passes one can measure one of the angles $\alpha_{\mathrm{V}}$ or $\beta_{\mathrm{V}}$. With interferometry on only one pass, as here, both angles have to be assumed independently. A common assumption is that the flow is parallel to the ice surface and normal to the topographic contours $\left(\alpha_{\mathrm{V}}=\alpha_{\mathrm{G}}, \beta_{\mathrm{V}}=\beta_{\mathrm{G}}\right)$.

Expression (2) and Equation (3) allow general estimates of the surface motion and the topographic relief that correspond to one fringe in Figure 3. Using $\theta=24.4^{\circ}, \beta_{\mathrm{V}}=0^{\circ}$, $\alpha_{\mathrm{V}}=\alpha_{\mathrm{G}}=2^{\circ}$, which are typical parameters for the study area (Table 1), we obtain

$$
v_{\|}\left(\Phi_{\mathrm{m}}=2 \pi\right)=2.47 \mathrm{~cm} \mathrm{~d}^{-1}
$$

and

$$
h\left(\Phi_{\mathrm{t}}=2 \pi\right)=410 \mathrm{~m},
$$

respectively.

For Black Rapids Glacier, center-line velocities of typically $10-15 \mathrm{~cm} \mathrm{~d}^{-1}$ cause $4-6$ fringes due to ice motion from the (stationary) margin to the center. The cross-glacier topography, which is typically $<20 \mathrm{~m}$, introduces only weak topographic modifications on the order of 0.05 fringes from margin to center, which propagate into an error of $\pm 0.12 \mathrm{~cm} \mathrm{~d}^{-1}$ in the motion signal. This error is small and we make no correction for it in our analysis. For longitudinal velocity variations, one would need to correct for the along-glacier topography, which introduces a linear trend of about $0.2 \mathrm{~cm} \mathrm{~d}^{-1}$ per $1 \mathrm{~km}$ horizontal distance for an ice surface slope of $2^{\circ}$.

\section{Co-registration of the interferogram to UTM coordinates}

The phase image of Figure 3 is given in pixel coordinates $(i, j)$, while the terrestrial survey data and topographic contours are

Table 1. Geometry parameters and velocities for the transverse profiles shown in Figures 5 and 6

\begin{tabular}{lccccccc}
\hline \multicolumn{1}{c}{ Site } & $h$ & $\theta$ & $\alpha_{\mathrm{G}}$ & $\beta_{\mathrm{V}}$ & $v_{\|}$winter & $v_{\perp}$ winter & $\alpha_{\mathrm{V}}$ \\
& $\mathrm{m}$ & $\circ$ & $\circ$ & $\circ$ & $\mathrm{cm} \mathrm{d}^{-1}$ & $\mathrm{~cm} \mathrm{~d}^{-1}$ & $\circ$ \\
& & & & & & & \\
\hline $14 \mathrm{~km}$ & 1730 & 24.7 & +2.0 & +28 & 12.8 & 0.82 & -1.7 \\
$15 \mathrm{~km}$ & 1700 & 24.6 & +2.0 & +22 & 12.3 & {$[+0.82]$} & -1.8 \\
$16 \mathrm{~km}$ & 1660 & 24.6 & +2.0 & +18 & 12 & - & {$[-1.8]$} \\
$18.5 \mathrm{~km}$ & 1580 & 24.4 & +1.9 & +12 & $\{10.8\}$ & $(+0.93)$ & $(-2.9)$ \\
$20 \mathrm{~km}$ & 1530 & 24.3 & +1.8 & +14 & 9.9 & +1.04 & -3.8 \\
$22 \mathrm{~km}$ & 1450 & 24.2 & +2.2 & +2 & $\{7.1\}$ & - & {$[-3.8]$} \\
$24.7 \mathrm{~km}$ & 1390 & 23.9 & +2.3 & +18 & $\{14.7\}$ & - & {$[-2.0]$} \\
$26.5 \mathrm{~km}$ & 1320 & 23.7 & +2.0 & \pm 0 & 9.6 & $(+0.67)$ & $(-2.0)$ \\
& & & & & & & \\
\hline
\end{tabular}

Notes: $\alpha_{\mathrm{G}}, \alpha_{\mathrm{V}}, \beta_{\mathrm{V}}$ and $\theta$ are defined in Figure 4. $v_{\|}$was obtained by scaling terrestrial velocity data of Heinrichs and others (1995) to winter 1992 using annual and seasonal corrections from Figure 2 and corresponding graphs for other sites from Heinrichs and others (1996). Values in curly brackets involved spatial interpolation. $v_{\perp}=v_{\mathrm{E}}$ for the 14 and $20 \mathrm{~km}$ sites is taken from Table 2. Values for other sites are assumed the same as that of an adjacent site (square brackets) or are calculated by matching the interferometric center-line velocity via $\alpha_{\mathrm{V}}$ to $v_{\|}$(round brackets). 
originally given in Universal Transverse Mercator (UTM) coordinates $(x, y)$. Co-registration of the two coordinate systems to pixel accuracy $(30 \mathrm{~m})$ requires a set of position tie points with both pixel and map coordinates known. The first choices for such tie points are surveyed SAR corner reflectors on the ground, which show up as bright spots in the amplitude image. Here, we instead used an interactive procedure to approximately co-register natural objects, like the ice margins of the main glacier and its tributaries. Such objects were identified on the amplitude or phase image and on a topographic map (Heinrichs and others, 1995). The mapping function

$$
(i, j)=\mathbf{P}(x, y)
$$

was restricted to a linear transformation, which includes translation, scaling, rotation and dilatation. The parameters of the linear transformation were iteratively optimized and the quality of the resulting co-registration can be evaluated from Figures 1 and 3. The remaining misregistration is due to non-linear distortion of the SAR image. This error was minimized for the vicinity of the $16 \mathrm{~km}$ site, where the accuracy of the co-registration should be better than $100 \mathrm{~m} \mathrm{(3-4}$ pixels). For a comparison of terrestrial and interferometric measurements of ice velocities near the center line, this accuracy is sufficient, as velocity changes here are usually small on scales of less than one ice thickness $(>400 \mathrm{~m}$ in most places). Near the glacier margins, spatial velocity variations are larger. For co-registrations worse than one pixel, this can make point-to-point velocity comparisons near the margin unreliable. When comparing entire transverse velocity profiles, however, the remaining misregistration in the transverse direction is easily identified as an alongprofile shift of the interferometric velocities with respect to the surveyed ones.

\section{Phase unwrapping}

In order to extract quantitative velocity information from Figure 3, the cyclic phase (wrapped phase) has to be restored into a continuous range. The presence of phase noise makes two-dimensional unwrapping challenging (e.g. Goldstein and others, 1988; Costantini, 1997; Fatland and Lingle, 1998). In contrast, one-dimensional phase unwrapping along lines in pixel space is straightforward: If the wrapped phase between two pixels changes by more than $\pi$, a cyclic phase jump is assumed. The latter is removed by simply adding $2 \pi \times$ (sign of the phase change) to all the phases ahead of the phase jump. Successive application of this rule gives the unwrapped phase.

When unwrapping along a line, phase noise can produce erroneous phase jumps. A simple procedure to eliminate these errors and to obtain meaningful transverse velocity profiles is as follows: A velocity profile in UTM coordinates

\footnotetext{
* Traditionally, velocities derived from terrestrial surveys are referred to by their horizontal $\left(v_{\mathrm{H}}\right)$ and vertical $\left(v_{\mathrm{V}}\right)$ components instead of by the surface-parallel/surface-perpendicular notation that we prefer for the interferometry. (Similarly, local mass balance is measured in the vertical direction instead of surface-perpendicular.) The relation between the two systems is $v_{\mathrm{H}}=v_{\|} \cos \alpha_{\mathrm{V}} / \cos \left(\alpha_{\mathrm{G}}-\alpha_{\mathrm{V}}\right)$ and $v_{\mathrm{E}}=v_{\mathrm{V}}-v_{\mathrm{H}} \tan \alpha_{\mathrm{G}}=v_{\perp}\left(\sin \alpha_{\mathrm{V}}-\tan \alpha_{\mathrm{G}}\right) / \sin \alpha_{\mathrm{G}}$ $\left.-\alpha_{\mathrm{V}}\right)$. Here, $v_{\mathrm{E}}$ is the so-called emergence velocity. However, due to the smallness of the angles $\alpha_{\mathrm{G}}$ and $\alpha_{\mathrm{V}}\left(\left|\alpha_{\mathrm{G}}\right|\right.$ $\left.<2^{\circ} ;\left|\alpha_{\mathrm{V}}\right|<5^{\circ}\right), v_{\|}=v_{\mathrm{H}}$ and $v_{\perp}=v_{\mathrm{E}}$ to better than $0.2 \%$.
}

is mapped to a line in pixel coordinates via Equation (5). Some ten parallel lines are selected on either side of the primary line. All lines have the same number of pixels and together they form the columns of a matrix, which represents a small rectangular sub-region around the desired velocity profile. This matrix is low-pass filtered along its rows (perpendicular to the velocity profile) to reduce the phase noise. Each column is then unwrapped one-dimensionally.

\section{Conversion of unwrapped phase to surface-parallel velocity}

This phase-unwrapping procedure was carried out for the seven rectangular regions shown in Figures lc and 3. From the unwrapped phase, transverse profiles of $v_{\|}$during the period 22-25 January 1992 can be calculated with Equation (3). The corresponding geometry parameters $\theta, \alpha_{\mathrm{V}}$ and $\beta_{\mathrm{V}}$ needed in the calculation are listed in Table 1 . They were derived for the profile centers but are assumed constant over the width of each profile. The following paragraphs represent a detailed investigation of the sensitivity of the phase-tovelocity conversion with respect to the individual geometry parameters.

Variations of the local incidence angle $\theta$ in the study area are small. The mean value $\theta=24.4^{\circ}$ applies to within $0.2^{\circ}$ for the main glacier trunk between the 15 and $22 \mathrm{~km}$ sites (Fig. 1c). Keeping $\theta$ constant would introduce only negligible error $(<2 \%)$ in Equation (3). The surface slope $\alpha_{\mathrm{G}}$ (column 4) was determined from survey data and topographic maps of Heinrichs and others (1995); for the part of Black Rapids Glacier between the 15 and $22 \mathrm{~km}$ sites, it is approximately constant at $\alpha_{\mathrm{G}}=+2 \pm 0.2^{\circ}$. The aspect of terrestrially measured velocity vectors $\beta_{\mathrm{V}}$ can differ by up to $15^{\circ}$ from the corresponding aspect $\beta_{\mathrm{G}}$ of the normal to the topographic contours (Fig. 1c). However, due to the favorable orientation of the glacier trunk within the study area $\left(\beta_{\mathrm{G}}, \beta_{\mathrm{V}} \ll 90^{\circ}\right)$, the error made by setting $\beta_{\mathrm{V}}=\beta_{\mathrm{G}}$ in Equation (3) is $<5 \%$. To make the consistency check of the interferometric with the terrestrial data as quantitative as possible, we nevertheless took $\beta_{\mathrm{V}}$ directly from the terrestrial survey data and used $\beta_{\mathrm{V}}=\beta_{\mathrm{G}}$ only for the interferometric profiles at 18.5, 22, 24.7 and $26 \mathrm{~km}$, which have no terrestrial measurements in their vicinity.

The slope of the velocity vector, $\alpha_{\mathrm{V}}$, is the geometry parameter that affects Equation (3) the most. Via the term $\sin \left(\theta-\alpha_{\mathrm{V}}\right)$, a small uncertainty in $\alpha_{\mathrm{V}}$ of $1^{\circ}$ translates into an error of $5 \%$ in Equation (3). For the case $\beta_{\mathrm{V}}=\beta_{\mathrm{G}}$ we can use Figure 4 to derive $\alpha_{\mathrm{V}}$ as

$$
\alpha_{\mathrm{V}}=\alpha_{\mathrm{G}}-\arctan \left(\frac{v_{\perp}}{v_{\|}}\right) .
$$

Most interferometric studies deal with large, ice-streamtype glaciers, where surface-parallel flow $\left(v_{\perp}=0\right)$ is a good assumption, and thus neglect the second term in Equation (6). However, the surface-parallel flow assumption is an oversimplification over most of a valley glacier. For the studied part of Black Rapids Glacier the additional deviations from surface-parallel flow are introduced by the surge-type nature of the glacier. Both effects are briefly summarized in the following.

Any steady-state glacier exhibits uplift $\left(v_{\perp}>0\right)$ in its ablation area and subsidence in its accumulation area $\left(v_{\perp}<0\right)$ to compensate for local mass balance. ${ }^{*}$ The ratio $v_{\perp} / v_{\|}$, which determines $\alpha_{\mathrm{V}}$ in Equation (6), is expected to be larger 
for valley glaciers than for ice streams. This is due to the higher mass-balance gradients and associated larger longitudinal strain rates of valley glaciers. Therefore $\alpha_{\mathrm{G}}$ can differ from $\alpha_{\mathrm{V}}$ by as much as $2-3^{\circ}$ for valley glaciers. On surgetype Black Rapids Glacier, which is far from steady state, this effect is additionally increased for two reasons. (i) The pronounced thickening in the upper ablation area during the quiescent phase of the glacier (Heinrichs and others, 1996) requires $v_{\perp}$ to be considerably more positive there. (ii) The surface-normal velocity $v_{\perp}$ additionally has a strong seasonality, with most positive values occurring during winter when the SAR interferometry was acquired. This is seen in Table 2, where we have calculated summer and winter values of $v_{\perp}$ for the 14 and $20 \mathrm{~km}$ sites from Heinrichs and others (1995, tables 9D and E). Both (i) and (ii) make $\alpha_{\mathrm{V}}$ negative and smaller than $\alpha_{\mathrm{G}}$ by as much as $5-6^{\circ}$. This can cause $v_{\|}$to be $>20 \%$ too high if $\alpha_{\mathrm{V}}=\alpha_{\mathrm{G}}$ is used in Equation (3).

Taking the geometry parameters constant across a transverse profile at their respective center-line values requires justification in the case of $\alpha_{\mathrm{V}}$. For a steady-state glacier with a local mass balance that is constant across the glacier width, the condition for a stationary surface along a transverse profile is $v_{\perp}=$ const. According to Equation (6), this is not compatible with $\alpha_{V}=$ const. Raymond (1971) showed that an initially flat cross-glacier topography, where $v_{\perp}$ is exclusively proportional to the longitudinal strain rate of the ice, is characterized by $v_{\perp} / v_{\|}=\tan \left(\alpha_{\mathrm{G}}-\alpha_{\mathrm{V}}\right)=$ const. In the ablation area, this flat topography evolves into a steady-state crown shape that causes a secondary, transverse ice flow directed towards the margins, which in turn modifies the surface-normal velocity distribution into $v_{\perp}=$ const. In the present case, we deal with the ablation area of a recovering surge-type glacier somewhere in between Raymond's initial and final cases. Additional complications stem from the morainal debris covering the southern margin of the glacier, which reduces local ablation and makes it non-uniform across the glacier width. Altogether, we judge the situation within the study area to be closer to Raymond's initial case of a flat cross-glacier topography, and consequently use $\left(\alpha_{\mathrm{G}}-\alpha_{\mathrm{V}}\right)$ as the basic (approximately constant) parameter throughout the study. For a situation closer to steady state, $v_{\perp}$ would replace $\alpha_{\mathrm{G}}-\alpha_{\mathrm{V}}$ ) as the basic parameter in Equation (3); as a result, transverse profiles of $v_{\|}$would have somewhat smaller values near the glacier margins.

In Figures 5 and 6, the resulting interferometric profiles of $v_{\|}$are shown. For $\alpha_{\mathrm{V}}$ taken from Table 1, results are given both for the individual columns of the unwrapped profile matrices and for their means, as thin and thick solid lines, respectively. The results for $\alpha_{\mathrm{G}}=\alpha_{\mathrm{V}}$ are shown for the means only, as thick dashed lines. Length along the profiles is given in pixels; one pixel corresponds to approximately $30 \mathrm{~m}$. The zero point of the velocity scale was identified as the minimum values of the velocity profiles. For the given image configuration these minima coincide with the bedrock margins of the glacier; the apparent rise of the velocity past these minima is due to the topographic rises of the lateral moraines (Equation (2)).

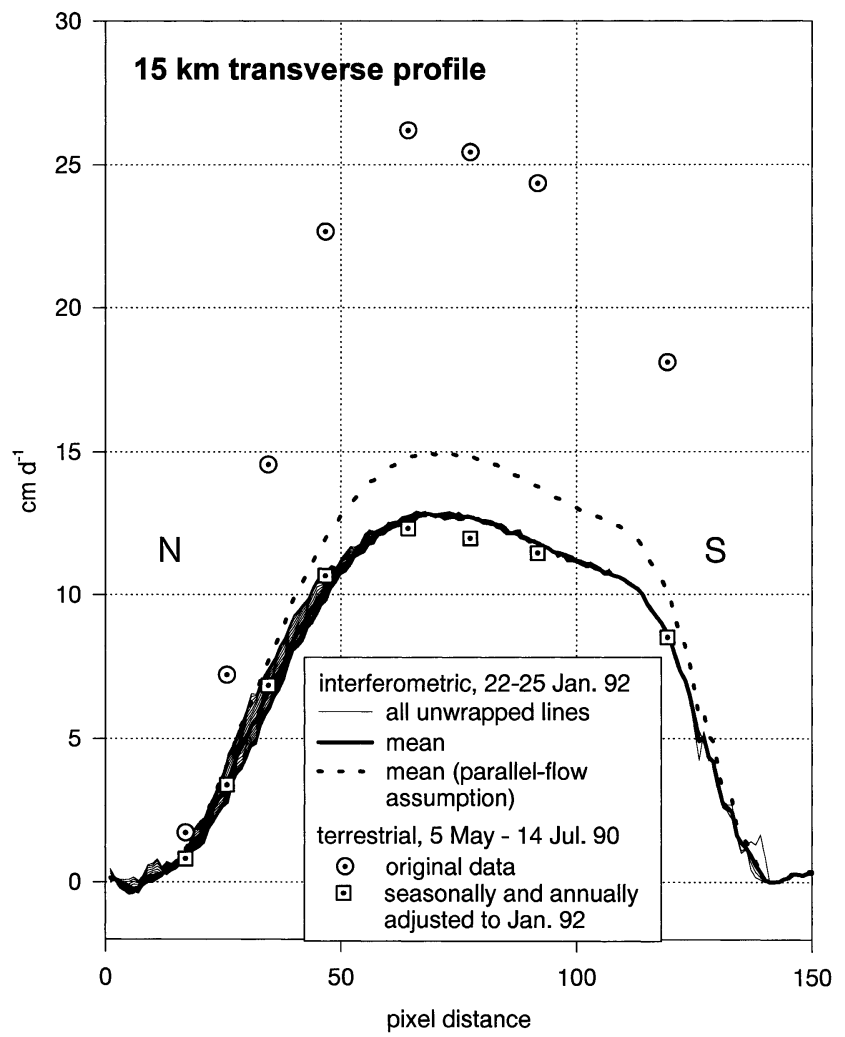

Fig. 5. Surface-parallel ice velocity, derived from SAR interferometry 22-25 January 1992, and from terrestrial surveying, 5 May-14 Fuly 1990 (Heinrichs and others, 1995), of a transverse profile at the $15 \mathrm{~km}$ site (Fig. 1c). The thin lines show all individual interferometric velocity profiles, chosen parallel at distances $< \pm 10$ pixels (about $300 \mathrm{~m}$ ) from the line of the terrestrial surface markers. The heavy line is the average of these individual profiles. The dashed line is the average obtained with the surface-parallel flow assumption. Circles denote the original terrestrial velocities; squares denote velocities that were scaled with seasonal (May-July to Fanuary) and interannual (1990-92) corrections from Figure 2.

Table 2. Surface-normal velocity $v_{\perp} \approx v_{\mathrm{V}}+v_{\mathrm{H}} \tan \alpha_{\mathrm{G}}$ for winter 1992 at the 14 and $20 \mathrm{~km}$ sites, calculated from terrestrially measured vertical $\left(v_{\mathrm{V}}\right)$ and horizontal $\left(v_{\mathrm{H}}\right)$ velocities

\begin{tabular}{|c|c|c|c|c|c|c|}
\hline Pole & Season & Time period & $\begin{array}{l}\text { Duration } \\
\text { months }\end{array}$ & $\begin{array}{c}v_{\mathrm{H}} \\
\mathrm{cm} \mathrm{d}^{-1}\end{array}$ & $\begin{array}{c}v_{\mathrm{V}} \\
\mathrm{cm} \mathrm{d}^{-1}\end{array}$ & $\begin{array}{c}v_{\perp} \\
\mathrm{m} \mathrm{a}^{-1}\end{array}$ \\
\hline \multirow[t]{3}{*}{ "14 km" } & Annual & 1 May 1991-4 May 1992 & 12 & 15.5 & -0.14 & +0.41 \\
\hline & Summer & 4 May 1992-23 Sept. 1992 & 4.5 & 20.1 & -0.96 & -0.25 \\
\hline & Winter & - & 7.5 & 12.7 & +0.36 & +0.82 \\
\hline \multirow[t]{3}{*}{ "20 km" } & Annual & 5 May 1991-5 May 1992 & 12 & 13.5 & +0.49 & +0.96 \\
\hline & Summer & 5 May 1992-23 Sept. 1992 & 4.5 & 19.0 & +0.16 & +0.82 \\
\hline & Winter & - & 7.5 & 10.1 & +0.68 & +1.04 \\
\hline
\end{tabular}

Notes: For the annual and summer period, $v_{\mathrm{H}}$ and $v_{\mathrm{V}}$ are direct results of three-dimensional pole position surveys, extracted from Heinrichs and others (1995, tables 9D and E). Corresponding winter values were interpolated according to winter value $=(12 \times$ annual value $-4.5 \times$ summer value $) / 7.5$. 

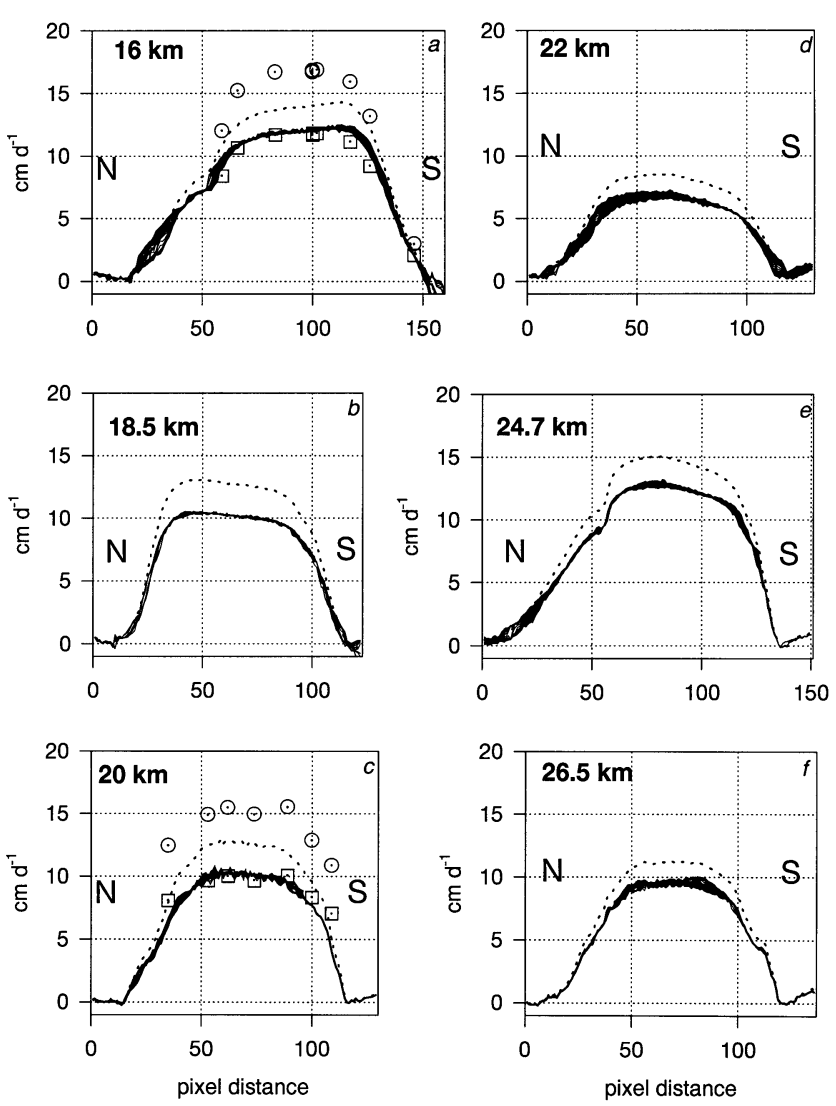

Fig. 6. Transverse profiles of interferometric surface velocity, 22-25 January 1992. Terrestrial velocity data are shown for the $20 \mathrm{~km}$ profile, acquired 24 April 1987 to 17 April 1988, from Heinrichs and others (1995) and for the $16 \mathrm{~km}$ profile, acquired 6-28 April 1996, from Truffer (unpublished data). Circles refer to the original data; squares represent velocities, which were scaled annually and seasonally using Figure 2.

\section{COMPARISON WITH TERRESTRIAL SURVEYED VELOGITY PROFILES}

Three of the seven interferometric profiles were chosen to enclose lines of surface markers near the 15,16 and $20 \mathrm{~km}$ sites that were previously surveyed with terrestrial methods. For a fourth line of surface markers, near $24 \mathrm{~km}$, we converted the interferometric phase for each marker separately. In the following we compare interferometric and terrestrial velocity measurements by scaling the original terrestrial measurements from their respective survey periods to the date of the interferometry (January 1992) by using the annual and seasonal corrections presented in Figure 2. We determine this scaling factor at the center line of each profile and assume that it is valid for the whole width of the profile. In Figures 5 and 6 the original data values are represented by circles, while the projected data are shown as squares (the results for the $24 \mathrm{~km}$ terrestrial profile are not shown in the figures but are discussed in the text).

\section{$15 \mathrm{~km}$ profile}

Here, the maximum terrestrial velocity was $26.2 \mathrm{~cm} \mathrm{~d}^{-1}$ over the period 23 May-14 July. According to Heinrichs and others (1995), interannual ratios of annual and seasonal velocities are similar, which allows us to use Figure 2 to project the terrestrially measured velocities to January 1992. At the $14 \mathrm{~km}$ site, close to our profile, the annual velocities in
1990 and 1992 were $15.4 \mathrm{~cm} \mathrm{~d}^{-1}$, while they were slightly lower in 1991 (14.7 $\mathrm{cm} \mathrm{d}^{-1}$; Fig. 2a). We therefore obtain $r_{\mathrm{a}}=$ 1.0 for the annual correction factor 1990-92. From Figure $2 \mathrm{~b}$, we obtain the long-term average of the velocity for the period 23 May-14 July as $\left(v_{\text {May }}+3 v_{\text {June }}+v_{\text {July }}\right) / 5=$ $24.6 \mathrm{~cm} \mathrm{~d}^{-1}$. The corresponding long-term average of the January velocity is $12.0 \mathrm{~cm} \mathrm{~d}^{-1}$, which leads to a seasonal correction factor $r_{\mathrm{s}}=12.0 / 24.6=0.49$ to project the terrestrial velocities to January. As there is no annual correction $\left(r_{\mathrm{a}}=1.0\right)$, this is also the total correction factor $r$.

For the $15 \mathrm{~km}$ profile there is another independent way to calculate the correction factor. In 1991 the automatic camera measured a January velocity of $10.1 \mathrm{~cm} \mathrm{~d}^{-1}$ for a marker near the $15 \mathrm{~km}$ profile. The location of this marker (shown as a star symbol in Figures 1c and 3) approximately coincides with the fourth marker of the $15 \mathrm{~km}$ profile (counted from the north side). Multiplying by the velocity ratio of the fifth (fastest) to the fourth marker of the $15 \mathrm{~km}$ profile $\left(r_{5 / 4}=\right.$ 1.16) and correcting for the slightly higher velocity in 1992 with respect to $1991\left(r_{\mathrm{a}}=1.05\right)$ we obtain $10.1 \times 1.16 \times 1.05=$ $12.3 \mathrm{~cm} \mathrm{~d}^{-1}$ for the terrestrial estimate of the January 1992 center-line velocity at the $15 \mathrm{~km}$ profile. We can then use the ratio of the center-line velocities, $r=12.3 / 26.2=0.47$, to scale the summer 1990 velocity profile to January 1992. This is in close agreement with $r$ obtained with the previous method.

In Figure 5, interferometric (with $v_{\perp}$ from Table 1) and adjusted terrestrial velocities (calculated with $r=0.47$ ) are in excellent agreement over the whole length of the profile. Assuming surface-parallel flow $\left(v_{\perp}=0\right)$, on the other hand, would overestimate the interferometric velocities by $20 \%$.

\section{$16 \mathrm{~km}$ profile}

At this profile, the terrestrial measurements over the period 6-28 April 1996 give a maximum velocity of $16.3 \mathrm{~cm} \mathrm{~d}^{-1}$. As before, we project the terrestrial velocities to January 1992, using the first of the two procedures presented in the previous paragraph. At the $14 \mathrm{~km}$ site, the annual velocities (Fig. 2a) were smaller in 1992 with respect to 1996 by a factor $r_{\mathrm{a}}=0.83$. From Figure $2 \mathrm{~b}$ we see that at the $15 \mathrm{~km}$ site the velocity in January is typically $r_{\mathrm{s}}=0.79$ times the velocity in April. Therefore we multiply the terrestrially measured velocities by $r=0.83 \times 0.79=0.65$ to project them to January 1992. Figure 6 a shows that for the entire profile, interferometric $\left(v_{\perp}\right.$ from Table 1$)$ and adjusted terrestrial velocities are in excellent agreement, while the surface-parallel flow assumption would make the interferometric velocities $16 \%$ too high.

\section{$20 \mathrm{~km}$ profile}

For the $20 \mathrm{~km}$ profile (Fig. 6c), which was terrestrially surveyed over an entire year (24 April 1987 to 17 April 1988), Figure 2 gives $r_{\mathrm{a}}=0.87$ and $r_{\mathrm{s}}=0.74$ (in this case $r_{\mathrm{s}}$ is the ratio of long-term January and annual velocities) to scale to January 1992 using $r=0.87 \times 0.74=0.64$. Again, interferometric velocities calculated with $v_{\perp}$ from Table 1 agree well with the adjusted terrestrial values. Interferometric velocities calculated with $v_{\perp}=0$ are $22 \%$ too high.

\section{$24 \mathrm{~km}$ profile}

The comparison of six terrestrial velocity measurements from 3 March 1975 to 25 March 1976 near 24 km (Figs 1c and 3) was hampered by the location of this profile at the 
confluence of the Loket tributary with the main glacier trunk. The associated (unmeasured) variations of surface slope and the large flow angles in the southern part of the profile, as well as the lack of a representative site for calculating seasonal and annual corrections, made it unfeasible to perform an accurate comparison as for the other profiles. Therefore, the absolute phase difference between the northern glacier margin and the vicinity of each marker was evaluated manually and converted to velocity using Equation (3). We then compared with the corresponding terrestrial measurements scaled to January 1992 with $r_{\mathrm{a}}=1.15$ (from Fig. 2a, $20 \mathrm{~km}$ site) and $r_{\mathrm{s}}=0.74$ (from Fig. 2b, $20 \mathrm{~km}$ site). Interferometric velocities obtained with the surface-parallel flow assumption $\left(v_{\perp}=0\right)$ were systematically higher $(16-35 \%)$ than the adjusted terrestrial velocities. No recent annual or seasonal values of $v_{\perp}$ exist for the individual surface markers, and the center-line value at $20 \mathrm{~km}$ is likely not representative. However, the observed bias suggests positive values for the actual $v_{\perp}$, meaning compressive flow at this profile, at least during winter.

\section{Error discussion}

The excellent agreement between terrestrial and SAR-derived velocities indirectly suggests the accuracy of the methods used in this study. Encouraged by the systematic error they correctly reveal for the surface-parallel flow assumption, we believe our methods to be accurate on the $5-10 \%$ level. Nevertheless, since the procedures used in converting phase to velocity and in scaling the terrestrial reference data each require a number of different steps that each contribute their uncertainty to the final result, we consider an independent discussion of potential errors worthwhile.

A first possibility is errors in the terrestrial measurements themselves, or in the procedure which was used to scale them to match the date of the SAR data acquisition. The expected errors of the optically surveyed annual velocity data and the monthly velocity data from the automatic camera measurements are all $<0.5 \mathrm{~cm} \mathrm{~d}^{-1}$. Errors in the scaling procedure, in particular using the average seasonal cycle to find seasonal corrections in individual years, could be much larger, in principle. However, we used two independent combinations of optical survey data and automatic camera measurements and arrived at very similar results for the $15 \mathrm{~km}$ profile, so this latter error seems to be small as well.

A second possibility is errors in the interferometric measurements. There are three ways in which these could occur: (i) There could be an error in evaluating the continuous phase from the wrapped phase. This is easily discarded, as in many parts of the phase image (Fig. 3) the glacier margin and the number of complete fringes from there to the center line can be unambiguously determined. The maximum difference in the interferometric velocities calculated with $v_{\perp}=0$ and $v_{\perp}$ from Table 1 is more than one fringe. (ii) There could be an error in converting unwrapped phase to velocity. Assuming that the published values of SAR parameters (geoid-satellite distance, nearslant range and slant-range increment) are correct, this is also very unlikely given the simplicity of the equations used to calculate the exact look angle $\alpha$ and the phase-to-velocity conversion (Equation (3)). (iii) The interferometric analysis could be unrepresentative due to the short time of observation, i.e. the glacier could be unusually fast or slow during the particular 3 day period of the SAR observation with re- spect to the January mean. In the quiescence mode of surgetype glaciers, however, spatially extensive short-term changes in glacier speed of $>10 \%$ are physically unlikely in mid-winter due to the lack of surface water input to the glacier sole. Furthermore, a preliminary evaluation of another SAR interferogram from 6-9 February 1992 shows no changes in the surface velocity field at the $5 \%$ level.

In summary, we have shown that the analyzed interferometric and terrestrial velocity data from Black Rapids Glacier are consistent on a quantitative basis. This lends confidence to both the interferometrically derived velocities and the conversions of the terrestrial data to the winter period. In particular, we believe the pronounced surfacenormal velocity component in mid-winter (suggested by interpolation of the terrestrial data) to be a solid result.

Quantitative comparisons between interferometric and terrestrial velocity data are rare for valley glaciers. We are aware of only one similar study which compares interferometric and terrestrial velocities of a valley glacier in quantitative detail (Vachon and others, 1996; Mattar and others, 1998). For Saskatchewan Glacier, Canada, Vachon and others (1996) present longitudinal profiles of interferometric velocity (acquired on 2-3 and 21-22 November for an ascending orbit), together with the velocities of two surface markers surveyed from September through December of the same year. One of the markers has about a $15 \%$ lower, the other about a $5 \%$ higher velocity than the interferometric velocity profiles. Mattar and others (1998) introduce an additional descending path to calculate $\alpha_{\mathrm{V}}$, while testing different assumptions for $\beta_{\mathrm{V}}$. Due to the scarceness of surface markers, however, and the fact that the descending orbit had a line of sight that was mostly perpendicular to the orientation of the glacier, no conclusive improvement of the comparison with terrestrial data was achieved.

The final section of the paper interprets the results of our analysis in terms of the dynamics of Black Rapids Glacier. We start out with a description of the two-dimensional characteristics of the surface-parallel velocity field, on the basis of Figures 3, 5 and 6, and then draw some connection with the seasonal cycle of the surface-normal velocities that was revealed by the terrestrial data in Table 2 as a by-product of our conversion procedures for the interferometric phase.

\section{DISGUSSION}

\section{Gharacteristics of the two-dimensional velocity field}

According to Figure 3, the velocity field at 15-20 km shows very little along-flow variation. This is the region where Heinrichs and others (1995) found low basal shear stresses and an abnormally high longitudinal-stress coupling length by modeling center-line velocities from ice depth and surface slope. Heinrichs and others interpret these as signs of strong, year-round sliding occurring at the base near the center line. From the surface velocity field alone we cannot contribute to discussion of this issue. A two-dimensional compilation of bed topography is needed to reveal the twodimensional distribution of basal shear stress via (three-dimensional) ice-flow modeling.

The velocity field has an interesting fine structure in the across-flow direction, represented in (i) the transverse tilt of the plateau of near-constant velocity, which determines the location of the actual velocity maximum on a transect, and 
(ii) the difference of the transverse strain rates at the northern and southern glacier margins. As can be seen in Figures 5 and 6 (or two-dimensionally in Figure 3), both (i) and (ii) change sign repeatedly along the glacier, which likely reflects corresponding changes of the transverse distributions of basal sliding and ice thickness. It seems possible that a line connecting the transverse velocity maxima traces a segment of the Denali fault.

Another large-scale feature in Figure 3 is the region of closed phase contours, where the Loket tributary enters the main glacier. Taking into account the different flow angle of this region, velocities are similar to those of the $15-20 \mathrm{~km}$ plateau. In the middle reach of the Loket, where terrestrial surveys suggest the velocity maximum of the entire glacier, ice flow is perpendicular to the satellite look direction and cannot be studied with the given interferometric image pair. A very large velocity gradient along the $24.7 \mathrm{~km}$ profile at about 50 pixels distance marks the boundary between the main glacier and the Loket tributary. The roles of "tributary" and "main glacier" are somewhat misleading as the Loket occupies more than two-thirds of the main glacier width. (A similar large velocity gradient for the $16 \mathrm{~km}$ velocity profile marks the boundary between the main glacier and a tributary which enters from the north side.)

In-between the $15-20 \mathrm{~km}$ velocity plateau and the confluence region of the Loket is a region where center-line velocity drops to about half its value on the high-velocity plateaus. Most of the drop occurs between the 20 and $22 \mathrm{~km}$ cross-sections (Fig. 6). Most likely this drop is caused by the entry of the Loket, leading to a reduction in surface slope, an increase in ice thickness and overall reduced velocity in this region.

\section{Seasonal changes of the ice-flow dynamics}

Our analysis (Table 2) reveals an interesting seasonal cycle of the surface-normal velocities in the upper ablation area. Ice flow changes from longitudinally extensive flow during summer to longitudinally compressive flow during winter. In the lower ablation area, ice flow is compressive yearround, with compression being only slightly larger during winter. The spatial pattern of this seasonal behavior is not resolved well enough to warrant a quantitative calculation. However, we can draw some interesting qualitative conclusions. In the upper ablation area, the winter value of the surface-parallel velocity component $\left(v_{\|}\right.$for 14,15 and $16 \mathrm{~km}$ sites in Table 1) gradually decreases down-glacier, as is expected for compressive flow. During the period of elevated surfaceparallel velocities (beginning with the surface-water-induced spring speed-up around June) the opposite must be true, i.e. $v_{\|}$must increase down-glacier in this region. In contrast, the longitudinal velocity gradient in the lower ablation area (20 km site) is largely unaffected by the speed-up. Concordant with Heinrichs and others' (1995) findings of low basal shear stress and an abnormally large longitudinalstress coupling length, a possible interpretation is that the $15-20 \mathrm{~km}$ region of the glacier as a whole moves disproportionately faster during summer than the upper glacier. A pronounced down-glacier increase of the spring speed-up amplitude, $\Delta v_{\|}=v_{\|}($summer $)-v_{\|}($winter $)$, over a short distance of $2-3 \mathrm{~km}$, beginning just above the upper end of the 15-20 km region, would be compatible with the observed summer subsidence at the $14 \mathrm{~km}$ site, while a largely constant $\Delta v_{\|}$down-glacier from there would be compatible with the only weak seasonal cycle of $v_{\perp}$ at the $20 \mathrm{~km}$ site. Large variations of $\Delta v_{\|}$between 8 and $14 \mathrm{~km}$, and small variations between 14 and $20 \mathrm{~km}$, are also suggested by Heinrichs and others (1996, fig. 7). The ultimate reason for the seemingly decoupled movement of the $15-20 \mathrm{~km}$ region must be connected to corresponding variations of the subglacial boundary conditions. An additional factor may be the interplay of the seasonal velocity variations of the Loket tributary and the main glacier trunk. The spring speed-up on the Loket is larger than that of the main body of the glacier near the confluence (Heinrichs and others, 1995). This should create a down-glacier pull of the Loket onto the main glacier trunk, which could force a flow increase and a decrease of longitudinal stress at the confluence. In the presence of low basal shear stress, the latter could initiate enhanced sliding of the $15-20 \mathrm{~km}$ region as a block.

\section{GONGLUSION}

The presented interferometric and terrestrial datasets are mutually consistent. This suggests our interferometric technique is accurate, as well as our methods of interpolating the terrestrial data in time through seasonal and annual corrections. SAR interferometry has potential to interpolate the sparse terrestrial velocity measurements over the surface of Black Rapids Glacier.

Terrestrial surveys on Black Rapids Glacier have shown that winter velocities closely follow interannual trends of the annual and summer velocities. SAR interferometry, which is usually restricted to winter conditions due to the required phase coherence, should therefore be suitable for monitoring evolution of the velocity field of surge-type glaciers during their quiescent phases.

For the studied part of the ablation area of Black Rapids Glacier, it was crucial to consider surface-normal velocities in order to achieve quantitative agreement between interferometric and terrestrial measurements. With the surfaceparallel flow assumption, interferometric velocities were systematically too high, on the order of $20 \%$. An increased bias of the parallel-flow assumption for steady-state valley glaciers with respect to ice streams is expected from the higher mass-balance gradients of these glaciers. For nonsteady-state glaciers, such as Black Rapids, recovering from a previous surge, this effect is reinforced.

Supported by the interferometry, an analysis of terrestrial data revealed an interesting seasonal cycle of the surfacenormal velocity component in the ablation area of Black Rapids Glacier. In the upper ablation area the surface-normal velocity is negative during summer $\left(-0.25 \mathrm{~cm} \mathrm{~d}^{-1}\right.$ in 1991 at the $14 \mathrm{~km}$ site) and positive during winter $\left(+0.82 \mathrm{~cm} \mathrm{~d}^{-1}\right.$ in January 1992 at the $14 \mathrm{~km}$ site). In terms of strain, this means a switch from surface subsidence or extending flow during summer to surface rise or compressive flow during winter. The behavior of the surface-normal velocity component contrasts with that of the surface-parallel component, which has its maximum during summer and its minimum in mid-winter. In the lower ablation area, at the $20 \mathrm{~km}$ site the seasonal cycle of the surface-normal velocity is less pronounced $\left(+0.85 \mathrm{~cm} \mathrm{~d}^{-1}\right.$ in summer; $+1.0 \mathrm{~cm} \mathrm{~d}^{-1}$ in winter $)$.

\section{AGKNOWLEDGEMENTS}

We are grateful to M. Truffer, M. Nolan and T. Heinrichs for 
providing electronic copies of their survey data; to K. Echelmeyer and C. Lingle for interesting discussion and for commenting on earlier versions of the manuscript; and to $\mathrm{R}$. Bindschadler, J. Mohr and an anonymous reviewer for their advice and constructive criticism throughout the review process. We also thank W. Harrison for valuable scientific and personal advice. Part of this research was supported by U.S. National Science Foundation grants OPP-9214954 and OPP-9423477. Financial support by the German Aerospace Research Establishment (DLR) for preparation of our manuscript is acknowledged.

\section{REFERENCES}

Bindschadler, R. 1982. A numerical model of temperate glacier flow applied to the quiescent phase of a surge-type glacier. f. Glaciol., 28(99), 239-265.

Clarke, T. S. 1991. Glacier dynamics in the Susitna River basin, Alaska, U.S.A. 7. Glaciol., 37(125), 97-106.

Constantini, M. 1997. A phase unwrapping method based on network programming. In Fringe 96 Workshop on ERS SAR Interferometry, 30 September-2 October 1996, Zürich. Proceedings. Noordwijk, European Space Agency, 261-272. (ESA Publication SP-406.)

Fatland, D. R. and C. S. Lingle. 1998. Analysis of the 1993-95 Bering Glacier (Alaska) surge using differential SAR interferometry. f. Glaciol., 44(148), $532-546$.

Goldstein, R. 1995. Atmospheric limitations to repeat-track radar interferometry. Geophys. Res. Lett., 22(18), 2517-2520.

Goldstein, R. M., H. A. Zebker and C. L. Werner. 1988. Satellite radar interferometry: two-dimensional phase unwrapping. Radio Sci., 23(4), 713-720.

Goldstein, R. M., H. Engelhardt, B. Kamb and R. M. Frolich. 1993. Satellite radar interferometry for monitoring ice sheet motion: application to an Antarctic ice stream. Science, 262(5139), 1525-1530.

Gray, A. L., K. E. Mattar, D. Geudtner and P.W. Vachon. 1997. Experiments at CCRS using ERS tandem mode data. In Third ERS Scientific Symposium, 17-21 March 1997, Florence, Italy. Proceedings. Vol. 2. Frascati, Italy, European Space Agency, 1001-1006. (ESA Publication SP-414.)

Hannsen, R. F., S. Lehner and I. Weinreich. In press. Atmospheric heterogeneities from ERS tandem SAR interferometry and sea surface images. In 98 CEOS-SAR Calibration and Validation Workshop, Nordwijk. Proceedings. Nordwijk, European Space Agency, 33-39. (ESA Publication WAAP-138.)

Harrison, W. D., K. A. Echelmeyer, E. F. Chacho, C. F. Raymond and R. J. Benedict. 1994. The 1987-88 surge of West Fork Glacier, Susitna Basin, Alaska, U.S.A. 7. Glaciol., 40(135), 241-254.

Heinrichs, T. A., L. R. Mayo, R. S. March and D. C. Trabant. 1995. Observations of surge-type Black Rapids Glacier, Alaska, during a quiescent period, 1972-92. U.S. Geol. Surv. Open File Rep. 94-512.

Heinrichs, T. A., L. R. Mayo, K. A. Echelmeyer and W. D. Harrison. 1996. Quiescent-phase evolution of a surge-type glacier: Black Rapids Glacier, Alaska, U.S.A. J. Glaciol., 42(140), 110-122.

Kamb, B. 1987. Glacier surge mechanism based on linked cavity configuration of the basal water conduit system. F. Geophys. Res., 92(B9), 9083-9100.

Kostecka, J. M. and I. M. Whillans. 1988. Mass balance along two transects of the west side of the Greenland ice sheet. F. Glaciol., 34(116), 31-39.

Mattar, K. E., P.W. Vachon, D. Geudtner, A. L. Gray, I. G. Cumming and M. Brugman. 1998. Validation of alpine glacier velocity measurements using ERS tandem-mission SAR data. IEEE Trans. Geosci. Remote Sensing, GE-36(3), 974-984.

Raymond, C. F. 1971. Determination of the three-dimensional velocity field in a glacier. F. Glaciol., 10(58), 39-53.

Vachon, P.W., D. Geudtner, K. Mattar, A. L. Gray, M. Brugman and I. Cumming. 1996. Differential SAR interferometry measurements of Athabasca and Saskatchewan glacier flow rate. Can. 7. Remote Sensing, 22(3), 287-296. 